\title{
The role of smart grids in case of bushfire in Australian Kinglakes, Victoria (overveiw)
}

\author{
M. Alzoubi*, A. Maung Than Oo, A. Stojcevski \\ School of Engineering, Faculty of Science Engineering \& Built Environment, Deakin University, Australia
}

\begin{abstract}
This review article defines and highlights the role of smart grids in case of bushfire. It proposed an early warning and evacuation system based on Australian regions' geographical and climatic information in particular the region of Kinglake in the State of Victoria, Australia. The proposed system is able to detect, alarm, help to evacuate as well as to extinguish fire especially in easy burning wild and remote areas such as areas in the Victorian Kinglakes region
\end{abstract}

Keywords: Smart grid, climatic, early warning system

\section{Introduction}

State of Victoria experienced extreme fire weather conditions. On Saturday $7^{\text {th }}$ of February 2009 that led to the tragic losses. This day is known as Black Saturday across Australia. The deadly bushfires penetrated through the southern state of Victoria, resulting 173 people dead and 500 injured. In addition, around 2,000 homes were destroyed and statics estimated that the number of affected wildlife killed or injured could climb well into the millions [1], [2]. With its extended bush and extreme hot dry climate, Australia frequently suffered from dangerous bushfires, most known the 1939 Black Friday blaze in Victoria, leaving 71 people were killed, and the 1983 Ash Wednesday where fires in Victoria and South Australia, killed 75 people [3].

On Black Saturday, February the $7^{\text {th }}$, resident of Victoria Victorians were told to brace for the "worst day" in the state's history; weather forecasters reported of a record heat wave with temperatures soaring to $46.4{ }^{\circ} \mathrm{C}$, combined with gale-force winds of up to $90 \mathrm{~km} / \mathrm{hr}$. That day nearly 47 major fires spread in the State of Victoria. The most deadly fire is the Kilmore East fire, which killed 121 residents.

The Kilmore East fire was sparked by a faulty power pole near the township of Kilmore East, $60 \mathrm{~km}$ north of Melbourne. The flames quickly spread to most surrounded areas. Assisted by steep slopes and strong winds, this fire spread to nearby suburbs, including Kinglake where 38 people died, Strathewen where 27 died, and St. Andrews 12 were killed [3], [4]. The reason behind this high rate of death is the inefficient alarm and evacuation system where fire catching residents by surprise and trapping many of them in their homes.

Around the globe there are a significant research activities concerning early warning and evacuation systems in case of disasters worth mentioning Zhao et al have identified method of choosing optimal features used to intrusion detection system in coal mine disaster warning internet of things based on Immunity Algorithm [5]. Trongo et al. have design and development of an Integrated Web-based System for Tropical Rainfall Monitoring [6]. Chang et al have design a system of fire disaster based on Zigbee [7]. However there are no such investigations or research activities highlights or evaluate the role of smart grids in early warning and evacuation systems in case of Bushfire. Hence this research article will review and proposed a new early warning and evacuation system in case of Bushfire assisted by the existence of

\footnotetext{
* Manuscript received July 23, 2014; revised July 25, 2015.

Corresponding author: M. Alzoubi; Tel.:+0061-414740472; E-mail address: malzoubi@ deakin.edu.au.

doi: $10.12720 /$ sgce.4.2.139-145
} 
smart grids in Australian regions. Additionally the research will be benefited from the Kinglake geographical and meteorological data including temperature, wind speed and direction, atmosphere pressure, rainfall and relative humidity. The base function of the proposed system is using microcontrollers that able to sense and analyse the local meteorological conditions. The controllers input network are modified and built as in Fig. 1.

The output of the system will be registered in various scenarios using smart phone and tabs application (Apple store and Google play). These various scenarios are similar to conventional warning system as shown in Fig. 2 which is completely ambient temperature dependent. Additionally the proposed system will be able to communicate with the region's resident sending them text messages to their mobile phone or alternatively the resident can check the fire possibility using their smart phone. In case of extreme or sever fire possibility the system will help to evacuate the region and aid to direct resident to the safest and shortest route using the smart phone application or sending them direct text messages to their mobile phone. In case of fire the system sensors are able to assess the intensity of fire and sending a feedback signal through the controller to decide electricity network trip or area network isolation.

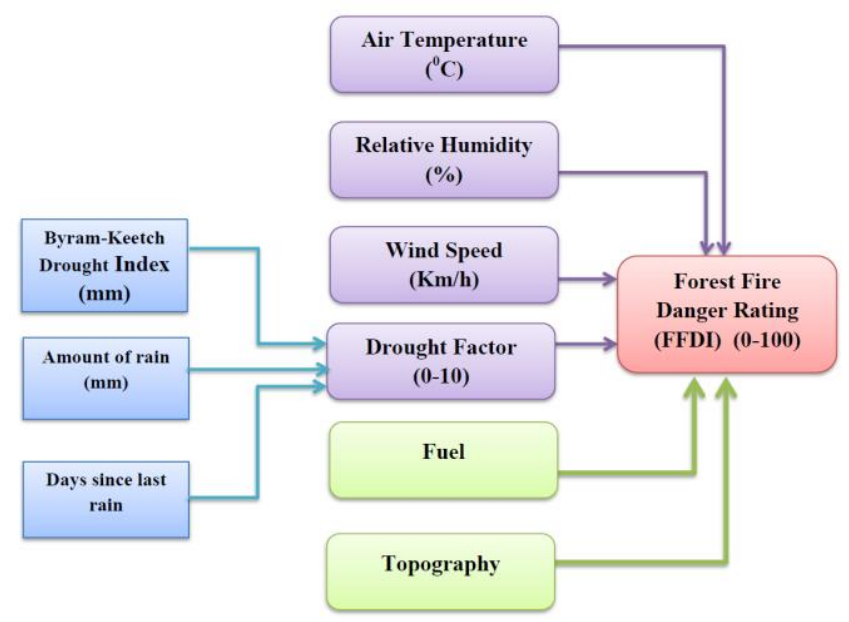

Fig. 1. Proposed fire danger index (FDI) system in Australia.

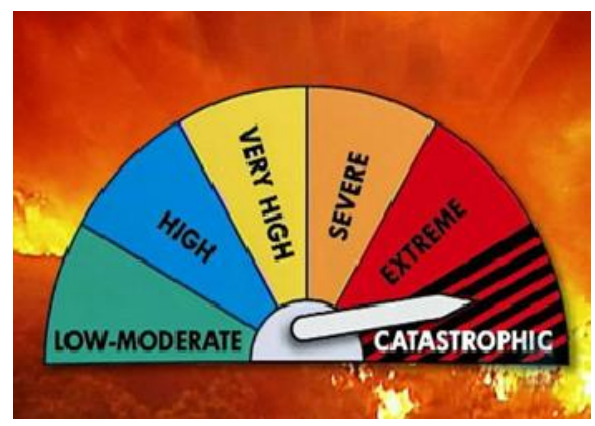

Fig. 2. Conventional fire warning system [8].

\section{Forest Fire Danger Rating Prediction Systems and Indices Use}

Fire danger rating systems are used to assess the potential for bushfire occurrence, fire spread and difficulty of fire suppression. Typically, fire danger rating systems combine meteorological information with estimates of the moisture content of the fuel to produce a fire danger index. The first fire danger system was installed in Australia in 1960s. The main purpose of the system was to protect people and their properties from the hazard of fire spreading. It has the ability to warn people from the danger of 
bushfire through agencies and government authorities which can reduce live losses and properties damage. In Australia, fire danger is determined using McArthur's forest and grassland fire danger metres. McArthur fire danger index or meter is the most widely index used in Australia, its statistical based system. The occurrence of the bushfires depends on wind speed, temperature, relative humidity, fuel and the amount of moisture in the fuel. Weather variables and type of the fuel play a crucial role on this system [9]-[11].

When bushfires occurred and developed it's depend on many factors. These factors interact together to create the fires the main factors that affect fire ignition are weather parameters, environmental factors and the nature of the fuel, some of these factors are variables such as wind speed, temperature, humidity, degree of curing, etc. while constant factors such as slop of the land. Many methods developed to convert the weather and fuel factors into fire danger index, this index show the level of fire danger that may threaten to the people [11]-[13].

\section{Fire Danger Index}

The Fire Danger Rating (FDR) is an assessment of the potential bushfire behavior. It used to provide a measure of the bushfire condition, threat and the potential impact on the community and environment [14], [15].

Since black Saturday in Victoria in 2009, a standardized fire danger rating (FDR) was adopted in all states of Australia. Its mission is to provide fire weather forecasts including temperature, wind speed and direction, relative humidity and dryness of vegetation during the fire season to bushfire agencies and authorities to determine the appropriate fire danger [16]. The FFDI is the base for the fire danger classification scheme used in Victoria in Australia, where fire danger level are classified as low, moderate, high, very high, severe, extreme or catastrophic according to the value of the FFDI as shown in Table 1.

Table 1: classification of fire danger level

\begin{tabular}{ll}
\hline \hline \multicolumn{1}{c}{ Category } & \multicolumn{1}{c}{ Forest fire danger index (FFDI) } \\
\hline Catastrophic (code red) & $100+$ \\
Extreme & $75-99$ \\
Severe & $50-74$ \\
Very high & $25-49$ \\
High & $12-24$ \\
Low to moderate & $0-11$ \\
\hline \hline
\end{tabular}

\section{Proposed System Input Network}

The proposed system will gather meteorological data including air temperature, wind speed, rain and relative humidity taking into account drought factor. The topographical details of the sight including Inclination of slope, direction of slope and ravines will be already addressed in the controller and will be assigned a strength value correspondent to its different variation. Another important factor which can be projected according to the sight proximity is fuel. This important factor will be categorized according to the fuel moisture content, the size and character of fuel (compact or grinded fuel), heat content, amount of fuel, continuity of fuel and the type of fuel.

\subsection{Fuel}

Dry fuel or the moister percentage in the fuel is an important factor that affecting the bushfire potential. The fuel moister content depends on the number of dry days, the more dry days the fuel becomes ready to ignite quickly. In addition, atmospheric pressure, temperature and relative humidity are important factors to control the bushfire. Thus, the relation between the fire dangers is directly proportional to the wind speed and inversely with fuel moisture content [17], [18].

When fuel load is big the fire will be hotter and the rate of burning is more. When fuel is concentrated with adequate spacing it will burn faster than heavily compacted. Smaller pieces of fuel such as branches, leaves and twigs burn quickly, particularly when they are dry and loosely arranged. Some types of grasses 
burn very rapidly, while larger fuels, such as tree trunks, do not burn as easily [18], [19]. Fuel Moisture Content (FMC) is a measure of the amount of moisture (water) in the fuel. Fuel moisture content or index is the moisture weight of a fuel and it's calculated as a percentage. For example, if a kilogram fuel sample is dried and weighs $700 \mathrm{~g}$, then the fuel moisture content is $43 \%$. Another example, if a kilogram fuel sample is dried and weighs $800 \mathrm{~g}$, then the fuel moisture content is $25 \%$.

\subsection{Drought factor}

Drought factor is a measure of fuel availability or a condition of dryness in the duff and upper soil layers that progress from total moisture saturation to an absence of available moisture (fuel dryness) [17]. It's an empirical of the estimate of the fuel moisture content (the amount of dry fuel available for burning) which is dependent on three factors, the first factor depend on the recent significant rainfall through direct wetting by rain and the second factor depend on the days since last rain and the third factor depend on the wetting from below via soil moisture which can be calculated using Keetch Byram Drought Index (KBDI) which is defined as the total rain in the most recent 24 hours with rain and the amount of rain needed to restore soil moisture to $200 \mathrm{~mm}$.

KBDI is a soil drought index with value ranges from 0 to 800 and is based on the soil capacity in 200 $\mathrm{mm}$ of water. The depth of soil required to hold $200 \mathrm{~m}$ of moisture varies. A prolonged drought (high KBDI) influences fire intensity largely because fuels have lower moisture content [18], [19].

Drought factor value range from $0-10$, with zero value of DF the potential of fire is very low due to the fuel is fully of moisture as the value of DF increases the potential of fire increase. With DF value of 10 it indicate that the fuel is very dry and has no moisture and the potential of fire is very high.

\subsection{Topography}

Areas topographic features can play an important role in influencing bushfire behavior and direction. These topographic factors include slope steepness, aspect, elevation and configuration of the land. Variations in these can cause dramatic changes in bushfire behavior [20], [21].

\subsection{Temperature}

A temperature is a numerical measure of hot or cold. It's measured in degrees and is the heat of the air mass. The Celsius scale $\left({ }^{\circ} \mathrm{C}\right)$ is used for common temperature measurements in most of the world many instruments are available in the market for temperature measurements its accuracy vary and depend on the manufacturers. Temperature has direct effect on the bushfires behaviour. High temperature is responsible to increase the temperature of grass and forest fuels to their ignition points. In addition temperature affects the atmospheric stability and wind speed. Fuel temperature affects directly bushfires behaviours and rate of spread [22].

The accuracy of temperature equipment is greatly dependent on the manufacturer, but also can be affected by usage. The accuracy of temperature can affect the value of fire danger index.

\subsection{Wind speed}

Wind speed is the rate of the movement of wind in distance per unit of time. it can be affected by terrain and obstacles such as buildings or trees. Cup-anemometer has been used to sense wind speed. An anemometer is useful because it rotates with the wind. The cup anemometer usually consists of three conical or spherical cups mounted on a rotating shaft. The speed of rotation is proportional to wind speed [22], [23].

Accuracy of the wind speed depends on proper maintenance of the cups, recorder and the power supply. The range of the wind speed is within $5 \%$ of the total measurement in normal conditions. Wind is the most important factor affecting the bushfires behaviours due to the fanning effect on the fires; wind can change direction and intensity which means more burning and more damage. Wind is very important in bushfires for the following reasons: 
- Its supply oxygen for the combustion process which make the fuel burning more rapidly.

- Reduce the grass and forest moisture which increase the drying of the fuel.

- Move the fires and heat toward the forest fuel in the path of fire

The main two elements of wind effect are direction and speed. These elements are usually associated with high to extreme fire. Wind can change speed, direction or it can be stormy. Strong and high wind will make the fire move faster and faster [24].

\subsection{Wind direction}

Wind direction is defined as the direction, which the wind is blowing from. A wind vane is also called a weather vane; it is a tool for measuring wind direction. For example, a westerly wind blows from the west to the east and northerly wind blows from the north to the south. Wind direction is usually reported in cardinal directions. For example, a wind coming from the south is given as 180 degrees; one from the east is 90 degrees. The accuracy of the wind direction instruments is within one degree in normal condition [13], [25].

\subsection{Relative humidity ( $\mathrm{RH} \%)$}

Relative humidity is the amount of water vapour in the air and it is measured as a percentage. The amount of the moisture in the atmosphere will affect the amount of moisture in the grass and forest fuel. When humidity is high bushfires will not spread because the grass and forest fuel contain have a high amount of moisture. On the contrary when the humidity is low the grass and fuel moisture levels will be low. In this case bushfires will spread very quickly. Relative humidity varies during the 24 hours, it's in lowest rate in the afternoon period and in the highest rate in the night and early morning this is due to relative humidity is affected directly from temperature [18].

Several instruments or equipment's are readily available and affordable for relative humidity measurements. These equipment's may provide accurate (plus or minus 2 to $5 \%$ ) relative humidity readings depending on environmental factors such as dust, moisture, fog, and gaseous contaminants can affect the sensors.

\subsection{Atmosphere pressure}

Atmosphere stability is important in bushfires it's the resistance of the atmosphere to vertical motion. Instability of the atmosphere will result in vertical movement in the air leading to increase the bushfires activities. The more difference in temperature resulting from bushfires in the atmosphere will create unstable conditions and then air move in both directions vertically and horizontally [26].

\subsection{Rainfall}

Rain has a direct effect on humidity and fuel moisture, when rain fall temperature drops down and wind become calm. Rainfall will dampen the surface of the grass and forest fuel to the stage that fires can't ignite the fuel. The amount of the rainfall has direct effect on the drought factor value [25].

\section{Accuracy of Measurements}

Accuracy, precision and uncertainty are used in connection with fire weather measurements and danger rating levels. The accuracy of a measurement is related to the equipment used in the field or the technique of measurement. The accuracy of measurement equipment is the degree of closeness of measurements of a quantity to the actual value. The precision of a measurement equipment usually related to repeatability and it's related to the degree of repeated measurements under unchanged conditions [21].

A measurement of equipment can be accurate but not precise, precise but not accurate, neither, or both. For example, if an experiment results contains a systematic error, then increasing the sample size will increase precision but does not improve accuracy. On the other side, reduce or eliminate the systematic error will improve the accuracy but not change precision. When the equipment having an accuracy of \pm 1 
units. It means that a series of measurements of some constant property made with the instrument were mostly (99\% of the time) within one unit of the correct value [10], [14].

FDI daily calculations for a specific area will result in an estimate of fire potential for that area at that time. Because the FDI System is designed entirely as a function of weather parameters, forecast FDI values can be calculated from the forecast values of the necessary weather parameters [17].

The main problem in calculating the FDI is the difficulty in forecasting the wind parameter. To the FDI calculations are very sensitive wind speed parameters small variation in wind speed will increase the value of the FDI depending on the drought factor value.

Nowadays sensors are used widely to measure the metrological variables and sensors having different accuracy measurement depending on the manufacturer and maintenance. A sensor is a converter device that detects and responds to some type of input from the physical environment such as temperature, light, humidity, heat, motion, wind speed, moisture, pressure, or anything related to the environmental phenomena. The output is generally a signal that is converted to human readable display at the sensor location or transmitted electronically over a network for reading or further processing [10], [14].

\section{Discussion}

Most of Fire warning and evacuation systems researched have been mostly devoted to display fire possibility in busy roads and motorway. Most of Bushfire especially in Kinglake area spread wide and fast due to the nature of the region as well as the previously discussed parameters. Relying on direct eye sight to warn resident is not efficient and lost of lives are expected. Designing a new way of early warning system that can warn, help people to evacuate as well as guide them to safest exits must be adopted and supported by Australia and the rest of the globe. The new strategy will be able to update resident using their smart phones and pads. In addition the proposed system is able disconnect wholly or partially the electricity network to prevent a wide spread of bushfire.

The controller's input parameters mentioned in this paper will allow design engineers and developers to design and deliver an optimum early warning and evacuation system that can compete with the conventional systems and able to provide suitable control solutions in Australian electricity network. Yet Bush fire smart grid's early warning and evacuation system has not been assessed under influence of the Kinglage hash climate which will be done for the Victorial reqion, Australia.

\section{Conclusions}

In Australian Victorians regions, Bushfire is rising which leads to more losses of lives and properties. Early warning systems have the ability to minimize losses and danger of bushfire. Accordingly this article presented a review on smart grid early warning and evacuation system. The paper firstly defined the factors to be taken into account when designing the proposed system. Then the paper presented current and conventional fire warning systems and their disadvantages. Finally it highlighted the development of intelligent systems to improve the efficiency of control systems in firefighting.

Developing reliable and efficient smart grid's early warning and evacuation system in case of Bush fire is essential. In the literature it is found that the objective of conventional fire warning system is to warn and help to evacuate resident. Thus the proposed smart grid early warning system proved significant advantages in processes by saving lives and property. Because this technology is an add-on to existing conventional control systems, it also can open new application fields for firefighting control systems in the market of grid automation and buildings while maintain accuracy of working environment.

\section{References}

[1] Australian Government. B.o.M. (2014). Bushfires in victoria, 7-8 February 2009. [Online]. Available: http://www.bom.gov.au/vic/sevwx/fire/20090207/20090207_bushfire.shtml

[2] Britannica AFAE. (2009). The Australian "Black saturday" bushfires of 2009. [Online]. Available: http://www.bom.gov.au/vic/sevwx/fire/20090207/20090207_bushfire.shtml 
[3] Cameron PA, et al. Black saturday: The immediate impact of the February 2009 bushfires in Victoria, Australia. Med J. Aust., 2009;191(1):11-16.

[4] Whittaker J, et al. Community safety during the 2009 Australian'Black Saturday'bushfires: An analysis of household preparedness and response. International Journal of Wildland Fire, 2013;22(6):841-849.

[5] Zhao JW, et al. Method of choosing optimal features used to intrusion detection system in coal mine disaster warning internet of things based on immunity algorithm. Progress in Mine Safety Science and Engineering II, 2014:157.

[6] Trono EM, et al. Design and development of an integrated web-based system for tropical rainfall monitoring. Procedia Environmental Sciences, 2014;20:305-314.

[7] Chang B, Zhang XR, Li LH. Design on monitoring system of fire disaster based on Zigbee CC2530. Applied Mechanics and Materials, 2013;397:1718-1722.

[8] (CFA)., C.F.A. Protecting lives and property. (2014). [Online]. Available: http://www.cfa.vic.gov.au/

[9] Blanchi R, et al. Environmental circumstances surrounding bushfire fatalities in Australia 1901-2011. Environmental Science and Policy, 2014;37:192-203.

[10] Sanabria LA, et al., Spatial interpolation of McArthur's forest fire danger index across Australia: Observational study. Environmental Modelling and Software, 2013;50:37-50.

[11] Clarke H, Lucas C, Smith P. Changes in Australian fire weather between 1973 and 2010. International Journal of Climatology, 2013;33(4):931-944.

[12] Blanchi R, et al. Meteorological conditions and wildfire-related houseloss in Australia. International Journal of Wildland Fire, 2010;19(7):914-926.

[13] Lucas C, Hennessy KJ, Mills G, Bathols J. Bushfire weather in southeast australia: Recent trends and projected climate change impacts. Bushfire Cooperative Research Centre, 2007.

[14] Dowdy AJ, et al. Index sensitivity analysis applied to the canadian forest fire weather index and the McArthur forest fire danger index. Meteorological Applications, 2010;17(3):298-312.

[15] Sharples JJ, et al. A simple index for assessing fire danger rating. Environmental Modelling \& Software, 2009;24(6):764-774.

[16] Wikipedia. (2014). Black saturday bushfires. [Online]. Available: http://en.wikipedia.org/wiki/Black_Saturday_bushfires

[17] Penman TD, et al. Examining the relative effects of fire weather, suppression and fuel treatment on fire behaviour - A simulation study. Journal of Environmental Management, 2013;131(0):325-333.

[18] Bedel AP, Mote TL, Goodrick SL. Climate change and associated fire potential for the south-eastern United States in the 21st century. International Journal of Wildland Fire, 2013;22(8):1034-1043.

[19] Cseresnyés I, Szécsy O, Csontos P. Fire risk in Austrian pine (Pinus Nigra) plantations under various temperature and wind conditions. Acta Botanica Croatica, 2011;70(2):157-166.

[20] Attiwill PM, Adams MA. Mega-fires, inquiries and politics in the eucalypt forests of Victoria, south-eastern Australia. Forest Ecology and Management, 2013;294(0):45-53.

[21] Sharples JJ, et al. Lateral bushfire propagation driven by the interaction of wind, terrain and fire. In: Proc. of 19th International Congress on Modelling and Simulation - Sustaining Our Future: Understanding and Living with Uncertainty 2011.

[22] Cheney NP, et al. Predicting fire behaviour in dry eucalypt forest in southern Australia. Forest Ecology and Management, 2012;280(0):120-131.

[23] Maddock N. Fire development in focus. Australian Journal of Emergency Management, 2013;28(1):50-51.

[24] Weil A. Fire Disasters. Saddleback Publishing: Irvine; 2012.

[25] Armitage OB, Lawson BD. Weather Guide for the Canadian Forest Fire Danger Rating System. Northern Forestry Centre, Canadian Forest Service, 2008.

[26] Healey J. Extreme Weather and Natural Disasters. The Spinney Press: Thirroul; 2012. 